\title{
Long non-coding RNA NEF inhibits proliferation and promotes apoptosis of laryngeal squamous cell carcinoma cells by inhibiting Wnt/ $\beta$-catenin signaling
}

\author{
XIANGYAN CUI, NING FANG, YU CUI, DONG XIAO and XIN WANG \\ Department of Otolaryngology-Head and Neck Surgery, The First Hospital of Jilin University, \\ Changchun, Jilin 130021, P.R. China
}

Received June 27, 2018; Accepted January 25, 2019

DOI: $10.3892 / 01.2019 .10150$

\begin{abstract}
The present study aimed to investigate the involvement of the recently identified long non-coding RNA neighboring enhancer of FOXA2 (lncRNA NEF) in laryngeal squamous cell carcinoma (LSCC). In this study, the expression levels of IncRNA NEF in tumor tissues and paired adjacent normal tissues were detected by reverse transcriptionquantitative polymerase chain reaction (RT-qPCR). Serum levels of NEF in patients with LSCC and healthy controls were also measured using RT-qPCR. Clinical and follow-up data of patients with LSCC were retrospectively analyzed. Diagnostic and prognostic values of serum NEF were evaluated by receiver operating characteristic curve and survival curve analysis, respectively. In addition, a NEF expression vector was constructed and transfected into human LSCC cells. The effects of NEF overexpression on cell proliferation, apoptosis and $\beta$-catenin expression were explored by Cell Counting kit- 8 cell proliferation assay, MTT assay and western blotting. NEF was significantly downregulated in tumor tissues compared with in paired adjacent normal tissues of patients with LSCC. Serum levels of NEF were significantly lower in patients with LSCC than in healthy controls. Low serum levels of NEF distinguished patients with LSCC from healthy controls, and also indicated shorter postoperative survival. NEF overexpression inhibited proliferation and promoted apoptosis of LSCC cells, and also downregulated $\beta$-catenin expression. No significant effects of Wnt agonist on NEF expression were identified; however, Wnt agonist reduced the effects of NEF overexpression on cancer cell proliferation and apoptosis. In conclusion, lncRNA NEF may inhibit proliferation and
\end{abstract}

Correspondence to: Dr Xin Wang, Department of Otolaryngology-Head and Neck Surgery, The First Hospital of Jilin University, 71 Xinmin Street, Changchun, Jilin 130021, P.R. China E-mail: rllfd87@163.com

Key words: laryngeal squamous cell carcinoma, long non-coding RNA neighboring enhancer of FOXA2, Wnt/ $\beta$-catenin signaling, proliferation, apoptosis promote apoptosis of LSCC cells by inhibiting Wnt/ $\beta$-catenin signaling.

\section{Introduction}

Although laryngeal squamous cell carcinoma (LSCC) accounts for only $2 \%$ of all types of cancer, this disease continues to be considered one of the major causes of cancer-associated mortality worldwide (1). Occurrence of LSCC is affected by various internal and external factors, and previous studies confirmed that human papillomavirus infection is associated with a small proportion of LSCC cases $(2,3)$. Surgical resection is the preferred treatment for LSCC at early stages and treatment outcomes are generally satisfactory (3). However, a large number of patients with LSCC are diagnosed in advanced stages and prognosis of these patients is extremely poor even subsequent to appropriate treatment (4). Therefore, to further improve the survival rates of patients with LSCC, particularly patients with distant tumor metastasis, remains a major task for clinicians.

The Wnt/ $\beta$-catenin signaling pathway is well characterized, with pivotal functions in the development of various types of malignancy, including LSCC $(5,6)$. Upregulated expression of $\beta$-catenin has been observed in cancer development and activated $\mathrm{Wnt} / \beta$-catenin signaling has been demonstrated to be involved in almost all critical aspects of the growth and metastasis of malignancies (7). Numerous studies have demonstrated that Wnt/ $\beta$-catenin achieves signal transduction through interactions with various signaling molecules, including long non-coding RNAs (lncRNA) $(8,9)$, which are a subset of non-coding RNAs composed of $>200$ nucleotides that serve pivotal roles in tumorigenesis (10). Neighboring enhancer of FOXA2 (NEF) is a recently identified lncRNA with a role as a tumor suppressor in hepatocellular carcinoma (11). In the present study, lncRNA NEF inhibited proliferation and promoted apoptosis of LSCC cells by inhibiting Wnt/ $\beta$-catenin signaling.

\section{Materials and methods}

Subjects and specimens. At total of 98 patients with LSCC were diagnosed and treated at The First Hospital of Jilin University 
(Changchun, China) between January 2011 and March 2013. The present study included 62 of these patients according to inclusion and exclusion criteria. Inclusion criteria: i) Patients were diagnosed and treated for the first time; and ii) patients completed the whole treatment and follow-up procedure. Exclusion criteria: i) Patients received treatment prior to surgery; ii) patients were transferred to other hospitals during treatment; iii) patients with other types of cancer; iv) patients with other severe diseases; v) patients with incomplete clinical and follow-up data; and vi) patients succumbed to other diseases or accidents during follow-up. The patients included in the present study comprised 28 males and 34 females, and were aged between 21 and 68 years, with a mean age of $45.1 \pm 7.1$ years. Tumor tissues, paired adjacent normal tissues and serum samples of these patients were available at the specimen library of The First Hospital of Jilin University and stored in liquid nitrogen at $-195^{\circ} \mathrm{C}$. The control group for this study included 48 healthy individuals who received routine physical examinations duirng the same time period. The control group included 22 males and 26 females, aged between 23 and 71 years, with a mean age of $44.3 \pm 7.9$ years. No significant differences in age, sex and other basic clinical data, including body mass index, blood glucose and blood pressure, were observed between patients with LSCC and controls. This study was approved by the ethics committee of The First Hospital of Jilin University, and all patients or their families gave written informed consent.

Reverse transcription-quantitative polymerase chain reaction $(R T-q P C R)$. Following total RNA extraction from tumor tissues, paired adjacent normal tissues, serum samples and in vitro cultured UM-SCC-17A cells using TRIzol ${ }^{\circledR}$ reagent (Invitrogen; Thermo Fisher Scientific, Inc., Waltham, MA, USA), RT was performed to synthesize cDNA using SuperScript III Reverse Transcriptase (Thermo Fisher Scientific, Inc.) under the following thermocycling conditions: $37^{\circ} \mathrm{C}$ for $25 \mathrm{~min}$ and $85^{\circ} \mathrm{C}$ for $10 \mathrm{~min}$. Using cDNA as the template, PCR was performed in a $20 \mu \mathrm{l}$ system, which was prepared using $\mathrm{SYBR}^{\circledR}$ Green Real-Time PCR Master Mixes (Thermo Fisher Scientific, Inc.). The following primers were used: lncRNA-NEF, forward 5'-CTGCCGTCTTAAACCAACCC-3', reverse 5'-GCCCAA ACAGCTCCTCAATT-3'; and $\beta$-actin, forward 5'-GACCTC TATGCCAACACAGT-3' and reverse 5'-AGTACTTGCGCT CAGGAGGA-3'. The reaction conditions for PCR were: $70 \mathrm{sec}$ at $95^{\circ} \mathrm{C}$, followed by 40 cycles of $15 \mathrm{sec}$ at $95^{\circ} \mathrm{C}$ and $35 \mathrm{sec}$ at $59^{\circ} \mathrm{C}$. Quantification cycle $(\mathrm{Cq})$ values were processed using the $2^{-\Delta \Delta \mathrm{Cq}}$ method (12) to normalize the expression of NEF for $\beta$-actin (endogenous control).

Cell line, cell culture and cell transfection. The human LSCC cell line UM-SCC-17A was purchased from Sigma-Aldrich (Merck KGaA, Darmstadt, Germany). Cells were cultured with American Type Culture Collection (ATCC)-formulated Eagle's Minimum Essential Medium (cat. no. 30-2003; ATCC, Manassas, VA, USA), containing $10 \%$ fetal bovine serum (Sigma-Aldrich; Merck KGaA), in an incubator $\left(37^{\circ} \mathrm{C}, 5 \%\right.$ $\mathrm{CO}_{2}$ ). Full-length NEF DNA surrounded by EcoRI cutting sites was amplified via PCR (performed by Shanghai GenePharma Co., Ltd., Shanghai, China) and was inserted into linearized pIRSE2-enhanced green fluorescent protein vector (Clontech
Laboratories, Inc., Mountainview, CA, USA) to construct a NEF expression vector (11). Prior to transfection, cells were cultured overnight to $80-90 \%$ confluence. Lipofectamine ${ }^{\circledR}$ 2000 reagent (cat. no. 11668-019; Invitrogen; Thermo Fisher Scientific, Inc.) was used to transfect NEF expression vectors $(15 \mathrm{nM})$ and empty vectors $(15 \mathrm{nM})$ into $5 \times 10^{5}$ cells. Untransfected cells were used as the control cells and cells transfected with an empty vector were used as negative control cells. Overexpression of NEF was confirmed by RT-qPCR prior to subsequent experiments, to make sure an overexpression rate of $>200 \%$ was reached (data not shown.). Cells were collected $24 \mathrm{~h}$ after transfection to perform subsequent experiments.

For treatment with Wnt agonist (a potent and selective activator of Wnt signaling; cat. no. sc-222416; Santa Cruz Biotechnology, Inc., Dallas, TX, USA), cells were treated with Wnt agonist at a dose of 5, 10 and $50 \mathrm{ng} / \mathrm{ml}$ for $24 \mathrm{~h}$ at $37^{\circ} \mathrm{C}$ prior to use.

In vitro cell proliferation assay. A Cell Counting kit-8 (CCK-8) assay was performed to detect the in vitro proliferative ability of UM-SCC-17A cells. Following transfection, cells were collected, washed with PBS and dissolved in ATCC-formulated Eagle's Minimum Essential Medium to generate suspensions with a cell density of $3 \times 10^{4}$ cells $/ \mathrm{ml}$. Each well of a 96-well plate was filled with $0.1 \mathrm{ml}$ suspension containing $3 \times 10^{3}$ cells. Cell culture was performed in an incubator $\left(37^{\circ} \mathrm{C}, 5 \% \mathrm{CO}_{2}\right)$. CCK-8 solution (10 ml, Sigma-Aldrich; Merck KGaA) was added at 24, 48, 72 and $96 \mathrm{~h}$ after the beginning of incubation. After a further $4 \mathrm{~h}$ at $37^{\circ} \mathrm{C}$, optical density values were measured using Fisherbrand ${ }^{\mathrm{TM}}$ accuSkan $^{\mathrm{TM}}$ GO UV/Vis Microplate Spectrophotometer (Thermo Fisher Scientific, Inc.) at $450 \mathrm{~nm}$ to detect cell proliferation rate. For Wnt agonist treatment, cells were subjected to Wnt agonist treatment at a dose of $10 \mathrm{ng} / \mathrm{ml}$ for $24 \mathrm{~h}$ at $37^{\circ} \mathrm{C}$ prior to use.

Cell apoptosis assay. Cells were harvested and dissolved in serum-free medium to prepare cell suspensions $\left(5 \times 10^{4}\right.$ cells $\left./ \mathrm{ml}\right)$. A total of $10 \mathrm{ml}$ cell suspension was transferred to each well of a 6-well plate. Cells were cultivated for $48 \mathrm{~h}$ and, subsequently, digested with $0.25 \%$ trypsin. Cells were stained with Annexin V-fluorescein isothiocyanate (Dojindo Molecular Technologies, Inc., Kumamoto, Japan) and propidium iodide in the dark at room temperature for $20 \mathrm{~min}$, followed by flow cytometry using a BD FACSCelesta ${ }^{\mathrm{TM}}$ Flow Cytometer (BD Biosciences, San Jose, CA, USA). Data were analyzed using FCS Express 6 Flow Cytometry Software (De Novo Software, Glendale, CA, USA). For Wnt agonist treatment, cells were subjected to Wnt agonist treatment at a dose of $10 \mathrm{ng} / \mathrm{ml}$ for $24 \mathrm{~h}$ at $37^{\circ} \mathrm{C}$ prior to use.

Western blotting. Following total protein extraction using radioimmunoprecipitation assay solution (Thermo Fisher Scientific, Inc.), protein concentration was measured by bicinchoninic acid assay. SDS-PAGE (10\% gel) was performed, with $30 \mu \mathrm{g}$ protein loaded per lane, to separate proteins with different molecular weights. Gel transfer to PVDF membranes using an iBlot 2 Gel Transfer Device (Thermo Fisher Scientific, Inc.) was performed, followed by blocking with $5 \%$ skimmed milk for $1 \mathrm{~h}$ at room temperature. Subsequently, membranes were 


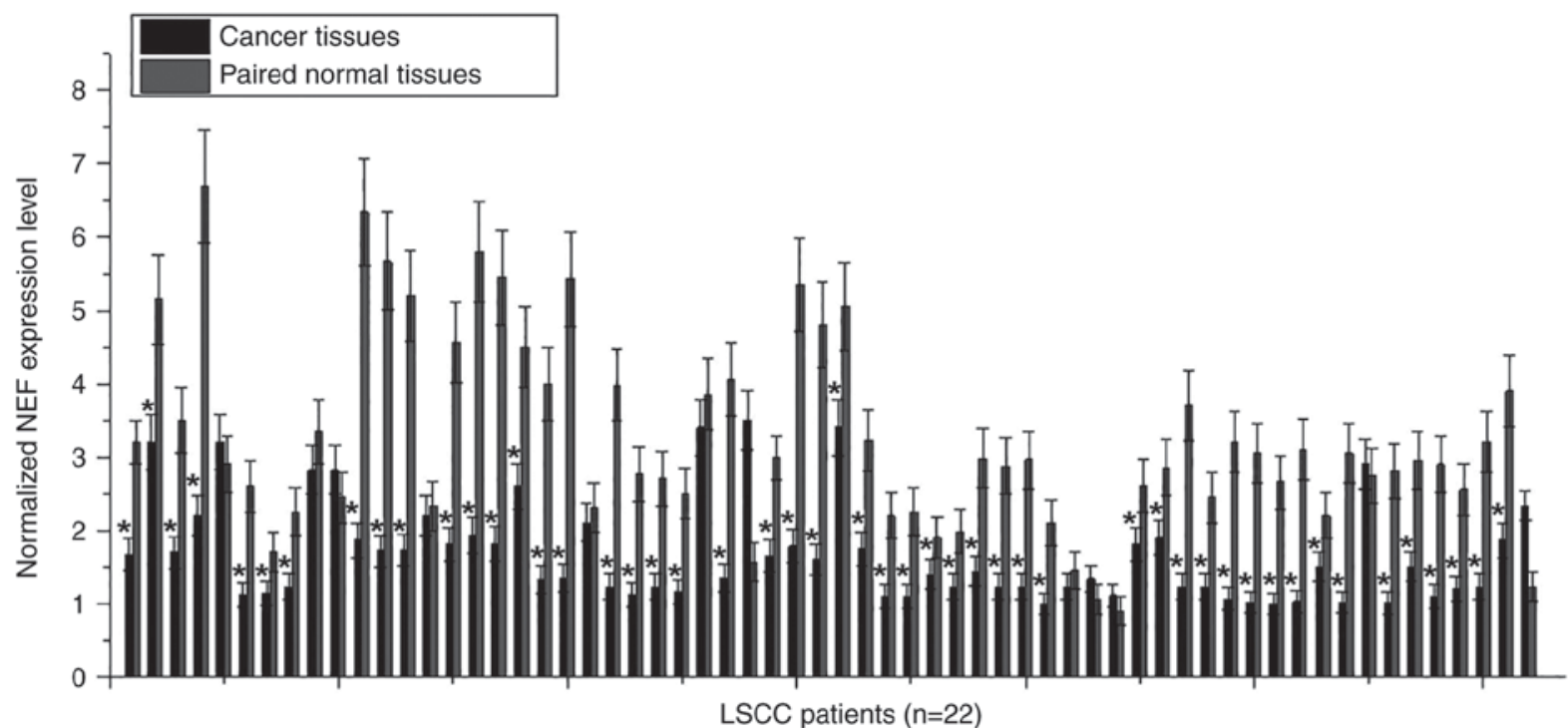

Figure 1. Comparison of NEF expression in tumor tissues and paired normal tissues in 62 patients with LSCC. "P $<0.05$ compared with paired normal tissues. LSCC, laryngeal squamous cell carcinoma; NEF, neighboring enhancer of FOXA2.

incubated with the following primary antibodies: $\beta$-catenin (rabbit anti-human; 1:2,000 dilution; cat. no. ab32572; Abcam, Cambridge, UK) and GAPDH (rabbit anti-human; 1:2,000 dilution; cat. no. ab9485; Abcam) overnight at $4^{\circ} \mathrm{C}$. The next day, membranes were washed and incubated with goat anti-rabbit immunoglobulin G-horseradish peroxidase secondary antibody (1:1,000 dilution; cat. no. MBS435036; MyBioSource, Inc., San Diego, CA, USA) for $2 \mathrm{~h}$ at room temperature. Signal development was performed using enhanced chemiluminescence (Sigma-Aldrich; Merck KGaA). $\beta$-catenin expression was normalized to GAPDH (endogenous control) using ImageJ v1.46 software (National Institutes of Health, Bethesda, MD, USA).

Statistical analysis. All experiments were performed in triplicate. GraphPad Prism 6.0 software (GraphPad Software, Inc., La Jolla, CA, USA) was used for all statistical analyses. NEF and $\beta$-catenin, as well as cell proliferation and apoptosis data, were recorded as means \pm standard deviation and compared by unpaired Student's t-test (between two groups) and one-way analysis of variance followed by least significant difference test (among multiple groups). A $\chi^{2}$ test was performed to analyze the association between serum NEF and clinicopathological data of patients with LSCC. Survival curves were plotted using the Kaplan-Meier method and further compared using log-rank test. Receiver operating characteristic (ROC) curve analysis was then utilized to evaluate the diagnostic value of serum NEF for LSCC with patients as true positive cases and healthy controls as true negative cases. $\mathrm{P}<0.05$ was considered to indicate a statistically significant difference.

\section{Results}

Comparison of NEF expression in tumor tissues and paired normal tissues in 62 patients with LSCC. Differential expression in tumor tissues and adjacent healthy tissues usually indicates the involvement of a certain gene in cancer. To investigate the involvement of NEF in LSCC, the expression of NEF in tumor tissues and paired normal tissues was detected in 62 patients with LSCC via RT-qPCR. As shown in Fig. 1, downregulation of NEF in tumor tissue compared with in adjacent healthy tissue was identified in 50/62 patients $(80.6 \%)$. Therefore, downregulation of NEF may be involved in the pathogenesis of LSCC.

Comparison of levels of serum NEF in patients with LSCC and healthy controls, and the diagnostic value. The RT-qPCR experiments detected the existence of circulating NEF in the serum of 62 patients with LSCC and 48 healthy controls. Serum levels of NEF were significantly lower in LSCC patients than in healthy controls $(\mathrm{P}<0.05$; Fig. $2 \mathrm{~A})$. ROC curve analysis was then utilized to evaluate the diagnostic value of serum NEF for LSCC. As shown in Fig. 2B, the area under the curve was 0.8782 with a standard error of 0.03664 and confidence interval of 0.8064 to $0.9500(\mathrm{P}<0.0001)$.

Association between levels of serum NEF and clinicopathological data of patients with LSCC. A $\chi^{2}$ test was performed to analyze the association between serum NEF and clinicopathological data of patients with LSCC. As shown in Table I, levels of serum NEF exhibited no significant association with sex, age, smoking and drinking habits, and existence of distant tumor metastasis $(\mathrm{P}>0.05)$. However, a significant association was identified between serum levels of NEF and tumor size $(\mathrm{P}<0.05)$.

Association between serum levels of NEF and postoperative survival. Tumor distant metastasis is a major cause of mortality in patients with LSCC. The data in Table I demonstrated that serum levels of NEF were not affected by the existence of distant metastasis. Therefore, follow-up data of all patients with LSCC were analyzed. Patients were divided into high $(n=31)$ and low $(n=31)$ groups according to the median serum level of NEF. Survival curves of these two groups were plotted using the Kaplan-Meier method and further compared using 

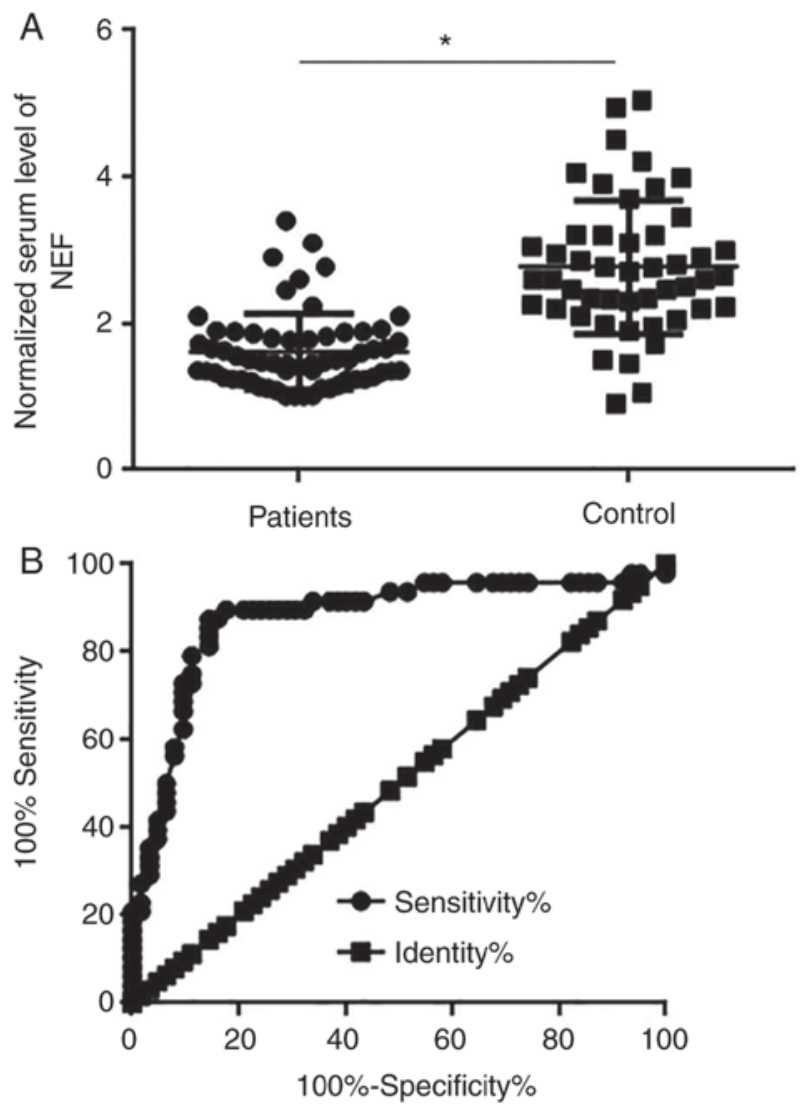

Figure 2. Comparison of serum levels of NEF in patients with LSCC and healthy controls, and the diagnostic value. (A) Comparison of serum levels of NEF in patients with LSCC and healthy controls. (B) Diagnostic value of serum NEF for LSCC determined by receiver operating characteristic curve analysis. ${ }^{*} \mathrm{P}<0.05$. LSCC, laryngeal squamous cell carcinoma; NEF, neighboring enhancer of FOXA2.

a log-rank test (Fig. 3). The overall survival rate of the low expression group was significantly worse than that of the high expression group $(\mathrm{P}=0.0249)$.

Effects of NEF overexpression on expression of $\beta$-catenin in the human LSCC cell line UM-SCC-17A. The data in Table I suggested that NEF may be involved in the growth of LSCC. The Wnt/ $\beta$-catenin signaling pathway serves a pivotal role in cancer growth by stimulating cancer cell proliferation and inhibiting apoptosis $(12,13)$. Therefore, the present study investigated the effects of $\mathrm{NEF}$ overexpression on $\beta$-catenin in the human LSCC cell line UM-SCC-17A. As shown in Fig. 4A, NEF overexpression significantly inhibited the expression of $\beta$-catenin $(\mathrm{P}<0.05)$. Conversely, following treatment with Wnt agonist (a potent and selective activator of Wnt signaling) at a dose of 5,10 and $50 \mathrm{ng} / \mathrm{ml}$, no significant effects on NEF expression (NEF expression levels were normalized to GAPDH as an endogenous control) were identified $(\mathrm{P}<0.05$; Fig. 4B).

Effects of NEF overexpression and Wht agonist on cell proliferation and apoptosis of UM-SCC-17A cells. As shown in Fig. 5A, NEF overexpression significantly inhibited the proliferation of UM-SCC-17A cells $(\mathrm{P}<0.05)$. In addition, NEF overexpression significantly promoted apoptosis of
UM-SCC-17A cells $(\mathrm{P}<0.05$; Fig. 5B and C). However, Wnt agonist treatment at a dose of $10 \mathrm{ng} / \mathrm{ml}$ significantly reduced the effects of NEF overexpression on proliferation and apoptosis of UM-SCC-17A cells $(\mathrm{P}<0.05$; Fig. 5A-C). The percentages of apoptotic cells in the control, negative control, NEF and $\mathrm{NEF}+$ Wnt agonist groups were 20.6, 20.66, 38.29 and 29.64\% of the total number of cells, respectively.

\section{Discussion}

Notably, the present study demonstrated that NEF, a recently identified lncRNA with characterized functionality only in hepatocellular carcinoma, may also inhibit the growth of LSCC (11). The action of NEF in LSCC may be achieved through interactions with the $\mathrm{Wnt} / \beta$-catenin signaling pathway.

The onset, development and progression of LSCC are accompanied by changes in a large set of lncRNAs, and these lncRNAs exhibit upregulated or downregulated expression patterns, to perform their roles as tumor suppressor genes or oncogenes (14). HOX transcript antisense RNA (HOTAIR), a well-studied oncogenic lncRNA, also exhibits upregulated expression in LSCC tissues compared with in paired adjacent healthy tissues, and the upregulation of HOTAIR may distinguish LSCC patients with poor postoperative survival from those with good survival chances following treatment (15). Conversely, lncRNA RP11-169D4 is significantly downregulated in LSCC tissues, and upregulation of RP11-169D4 inhibits tumor metastasis (16). Downregulation of NEF has been observed in hepatocellular carcinoma (11). In the present study, the majority of patients with LSCC exhibited downregulated NEF expression in tumor tissues compared with in paired adjacent normal tissues. This suggested that downregulation of NEF may be involved in the pathogenesis of LSCC.

Pathological examination is the gold standard for the diagnosis of human cancer; however, the application of biopsy is occasionally limited by its invasive nature. The development of human disease is usually accompanied by changes in certain substances in the circulatory system, such as blood flow, and blood biomarkers are currently used in a number of aspects of cancer diagnosis $(17,18)$. In the present study, serum levels of NEF were significantly lower in patients with LSCC than in healthy controls. ROC curve analysis further confirmed that low serum levels of NEF may be used to effectively distinguish patients with LSCC from healthy controls. Therefore, measurement of serum levels of NEF may be performed to aid the diagnosis of LSCC in cases where biopsy is not applicable. However, changes in the expression pattern of NEF may also form part of other diseases. Therefore, diagnosis based on multiple factors should be performed to improve accuracy.

Tumor metastasis is a major cause of mortality in cancer patients (19). No significant association between serum levels of NEF and the existence of distant tumor metastasis in patients with LSCC were observed in the present study, indicating that NEF is unlikely to be involved in the metastasis of LSCC. This is inconsistent with the role of NEF in in hepatocellular carcinoma, where NEF is involved in the regulation of tumor metastasis (11), indicating the different pathogenic pathways of these two malignancies. Subsequently, a survival curve analysis was conducted, which included all 62 patients with LSCC regardless of distant metastasis. The 
Table I. Association between levels of serum neighboring enhancer of FOXA2 and clinicopathological data of patients with laryngeal squamous cell carcinoma.

\begin{tabular}{|c|c|c|c|c|c|}
\hline Characteristic & Cases & High-expression & Low-expression & $\chi^{2}$ & P-value \\
\hline \multicolumn{6}{|l|}{ Sex } \\
\hline Male & 28 & 12 & 16 & \multirow[t]{2}{*}{1.04} & \multirow[t]{2}{*}{0.31} \\
\hline Female & 34 & 19 & 15 & & \\
\hline \multicolumn{6}{|l|}{ Age } \\
\hline$>45$ years & 33 & 15 & 18 & \multirow[t]{2}{*}{0.58} & \multirow[t]{2}{*}{0.45} \\
\hline$<45$ years & 29 & 16 & 13 & & \\
\hline \multicolumn{6}{|c|}{ Primary tumor diameter } \\
\hline$>3 \mathrm{~cm}$ & 41 & 15 & 26 & \multirow[t]{2}{*}{8.81} & \multirow[t]{2}{*}{0.003} \\
\hline$<3 \mathrm{~cm}$ & 21 & 16 & 5 & & \\
\hline \multicolumn{6}{|c|}{ Tumor distant metastasis } \\
\hline Yes & 33 & 15 & 18 & \multirow[t]{2}{*}{0.58} & \multirow[t]{2}{*}{0.45} \\
\hline No & 29 & 16 & 13 & & \\
\hline \multicolumn{6}{|l|}{ Smoking } \\
\hline Yes & 22 & 9 & 13 & \multirow[t]{2}{*}{1.13} & \multirow[t]{2}{*}{0.29} \\
\hline No & 40 & 22 & 18 & & \\
\hline \multicolumn{6}{|l|}{ Drinking } \\
\hline Yes & 29 & 16 & 13 & \multirow{2}{*}{0.58} & \multirow[t]{2}{*}{0.45} \\
\hline No & 33 & 15 & 18 & & \\
\hline
\end{tabular}

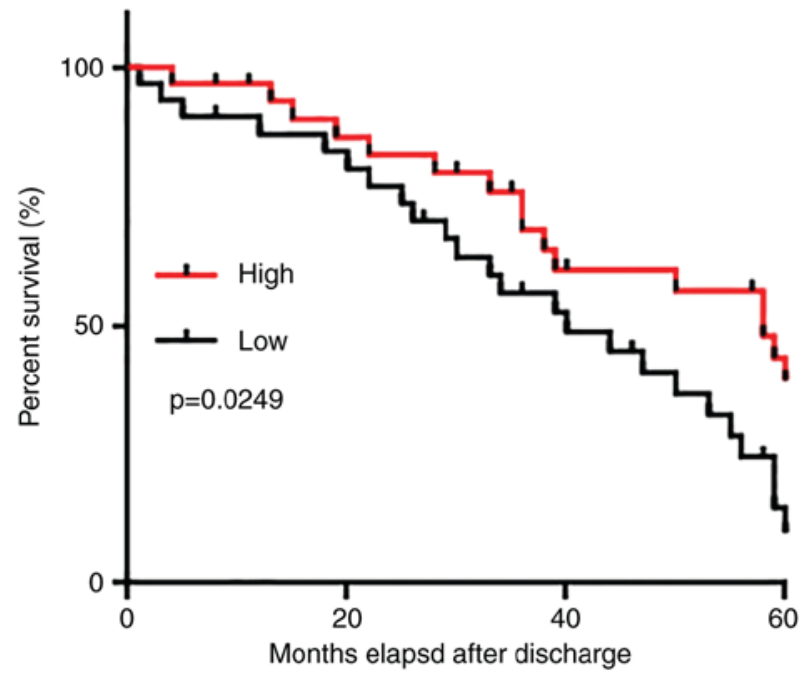

Figure 3. Survival curve analysis of the prognostic value of serum neighboring enhancer of FOXA2 for laryngeal squamous cell carcinoma.

survival curve comparison revealed that low serum levels of NEF were closely associated with poor postoperative survival of patients with LSCC, suggesting that serum levels of NEF may also serve as a potential prognostic biomarker for LSCC.

The $\chi^{2}$ analysis revealed that NEF expression was significantly associated with tumor size. Therefore, NEF is likely to be involved in the regulation of tumor growth. The in vitro cell proliferation assay demonstrated that NEF inhibited cancer cell proliferation and enhanced cancer cell apoptosis. Wnt/ $\beta$-catenin signaling has been proven to be involved in almost all critical aspects of the growth and metastasis of

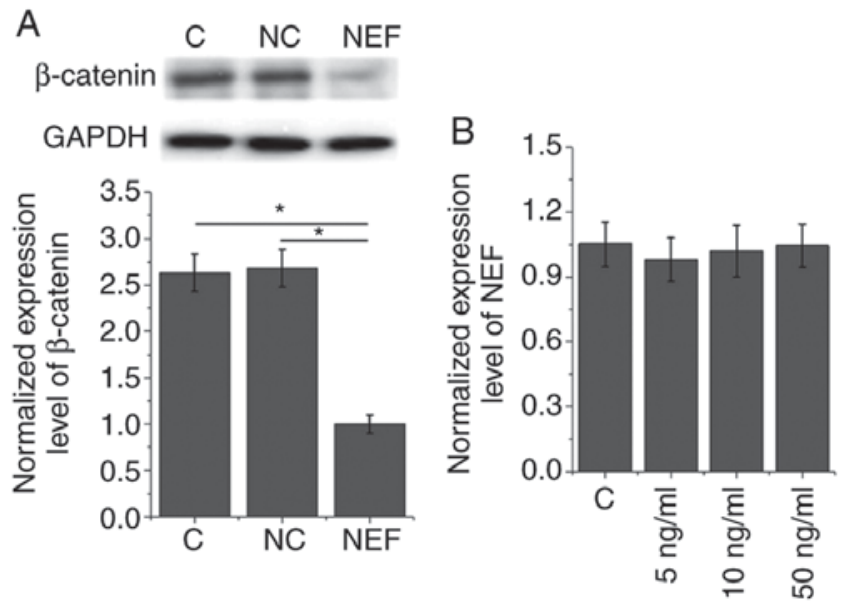

Figure 4. Effects of NEF overexpression on expression levels of $\beta$-catenin in the human LSCC cell line UM-SCC-17A. (A) Effects of NEF overexpression on expression levels of $\beta$-catenin. (B) Effects of Wnt agonist on NEF expression in the human LSCC cell line UM-SCC-17A. NEF expression levels were normalized to $\beta$-actin (endogenous control). ${ }^{*} \mathrm{P}<0.05$. $\mathrm{C}$, control; LSCC, laryngeal squamous cell carcinoma; NC, negative control (empty vector transfection); NEF, neighboring enhancer of FOXA2.

malignancies (7). In the present study, NEF negatively regulated $\beta$-catenin, while no significant effects of Wnt agonist on NEF expression were observed; however, Wnt agonist attenuated the effects of NEF overexpression on proliferation and apoptosis of LSCC cells. Therefore, NEF may be considered an upstream inhibitor of $\mathrm{Wnt} / \beta$-catenin signaling in the regulation of tumor growth in LSCC.

In conclusion, the present study demonstrated that NEF may act as a tumor suppressor lncRNA in LSCC, 

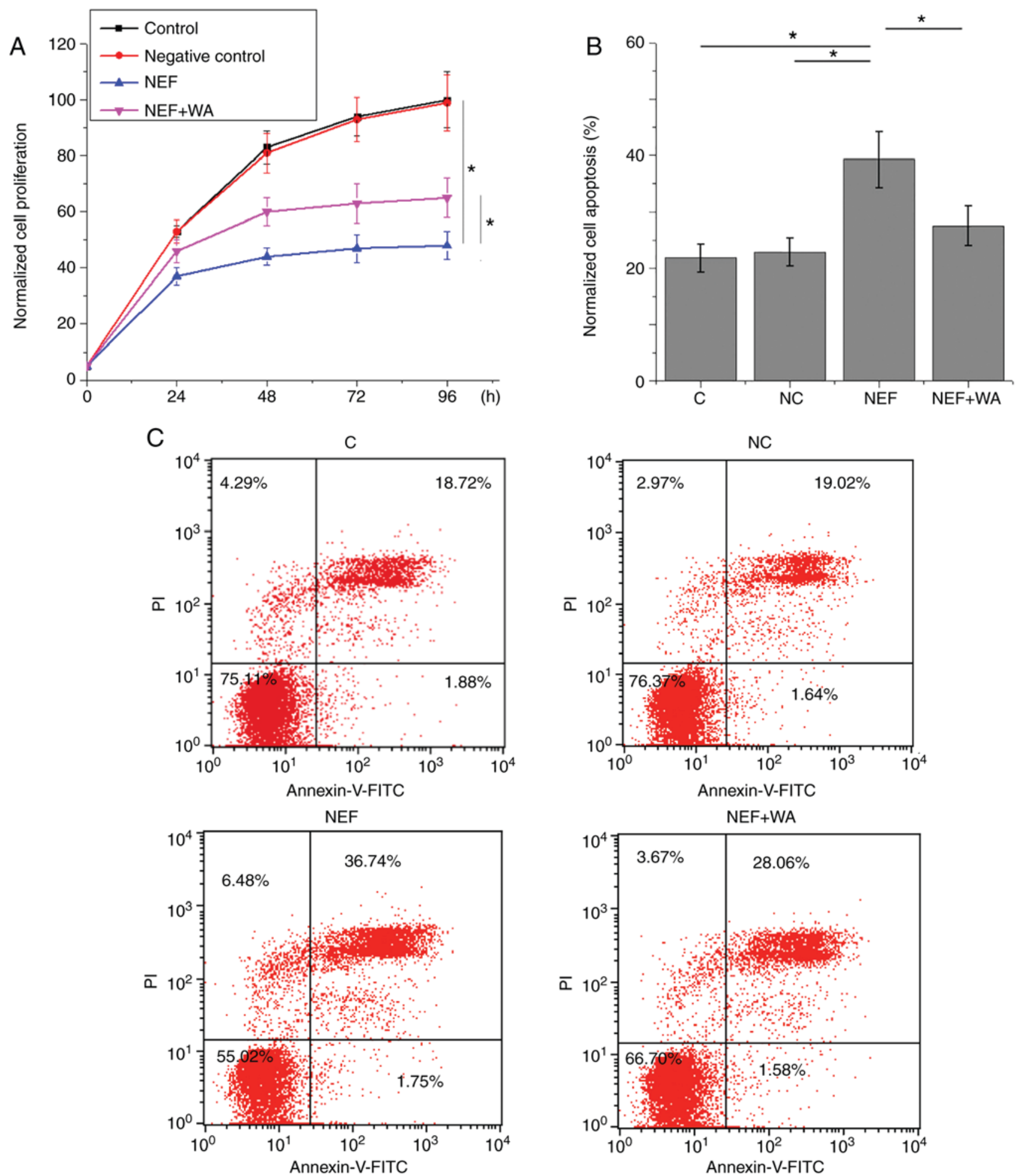

Figure 5. Effects of NEF overexpression and WA on proliferation and apoptosis of UM-SCC-17A cells. (A) Effects of NEF overexpression and WA on cell proliferation. (B and C) Apoptosis analysis of UM-SCC-17A cells. " P<0.05. C; control; FITC, fluorescein isothiocyanate; NC, negative control; NEF, neighboring enhancer of FOXA2; PI, propidium iodide; WA, Wnt agonist.

and NEF may inhibit the growth of LSCC by targeting the Wnt/ $\beta$-catenin signaling pathway. This study also revealed that serum NEF may serve as a promising diagnostic and prognostic biomarker for LSCC. However, the sample size in this study is relatively small. More patients will be included in future studies to further confirm the conclusions of the present study.

\section{Acknowledgements}

Not applicable.

\section{Funding}

No funding was received. 


\section{Availability of data and materials}

The datasets used and/or analyzed during the present study are available from the corresponding author on reasonable request.

\section{Authors' contributions}

XC, NF, and XW designed and carried out the study. XC, NF, $\mathrm{YC}, \mathrm{DX}$, and XW participated in experiments and statistical analysis. YC, DX and XW wrote the manuscript. NF, DX and XW revised the manuscript. All authors read and approved the final manuscript.

\section{Ethics approval and consent to participate}

The ethics committee of The First Hospital of Jilin University approved this study and all patients or their families gave written informed consent.

\section{Patient consent for publication}

Not applicable.

\section{Competing interests}

The authors declare that they have no competing interests.

\section{References}

1. Jemal A, Bray F, Center MM, Ferlay J, Ward E and Forman D: Global cancer statistics. CA Cancer J Clin 61: 69-90, 2011.

2. Halec G, Holzinger D, Schmitt M, Flechtenmacher C, Dyckhoff G, Lloveras B, Höfler D, Bosch FX and Pawlita M: Biological evidence for a causal role of HPV16 in a small fraction of laryngeal squamous cell carcinoma. Br J Cancer 109: 172-183, 2013.

3. Larbcharoensub N, Cheewaruangroj W and Nitiyanant P: Laryngeal sarcocystosis accompanying laryngeal squamous cell carcinoma: Case report and literature review. Southeast Asian J Trop Med Public Health 42: 1072-1076, 2011.

4. Zhang SY, Lu ZM, Luo XN, Chen LS, Ge PJ, Song XH, Chen SH and Wu YL: Retrospective analysis of prognostic factors in 205 patients with laryngeal squamous cell carcinoma who underwent surgical treatment. PLoS One 8: e60157, 2013.

5. Clevers $\mathrm{H}$ and Nusse R: Wnt/ $\beta$-catenin signaling and disease. Cell 149: 1192-1205, 2012.

6. Lee SH, Koo BS, Kim JM, Huang S, Rho YS, Bae WJ, Kang HJ, Kim YS, Moon JH and Lim YC: Wnt/ $\beta$-catenin signalling maintains self-renewal and tumourigenicity of head and neck squamous cell carcinoma stem-like cells by activating Oct4 J Pathol 234: 99-107, 2014.
7. Akiyama T: Wnt/beta-catenin signaling. Cytokine Growth Factor Rev 11: 273-282, 2000.

8. Xu D, Yang F, Yuan JH, Zhang L, Bi HS, Zhou CC, Liu F, Wang $F$ and Sun SH: Long noncoding RNAs associated with liver regeneration 1 accelerates hepatocyte proliferation during liver regeneration by activating $\mathrm{Wnt} / \beta$-catenin signaling. Hepatology 58: 739-751, 2013.

9. Cui Y, Zhang F, Zhu C, Geng L, Tian T and Liu H: Upregulated lncRNA SNHG1 contributes to progression of non-small cell lung cancer through inhibition of miR-101-3p and activation of Wnt/ $\beta$-catenin signaling pathway. Oncotarget 8: 17785-17794, 2017.

10. Schmitt AM and Chang HY: Long noncoding RNAs in cancer pathways. Cancer Cell 29: 452-463, 2016.

11. Liang WC, Ren JL, Wong CW, Chan SO, Waye MM, Fu WM and Zhang JF: LncRNA-NEF antagonized epithelial to mesenchymal transition and cancer metastasis via cis-regulating FOXA2 and inactivating Wnt/ $\beta$-catenin signaling. Oncogene 37: 1445-1456, 2018.

12. Galera-Ruiz H, Rios-Moreno MJ, González-Cámpora R and Galera-Davidson H: WNT pathway in laryngeal squamous cell carcinoma and nasopharyngeal carcinoma. Acta Otorhinolaryngol Ital 32: 122-123, 2012.

13. Xu J, Zhu X, Wu L, Yang R, Yang Z, Wang Q and Wu F: MicroRNA-122 suppresses cell proliferation and induces cell apoptosis in hepatocellular carcinoma by directly targeting Wnt/ $\beta$-catenin pathway. Liver Int 32: 752-760, 2012.

14. Shen Z, Li Q, Deng H, Lu D, Song H and Guo J: Long non-coding RNA profiling in laryngeal squamous cell carcinoma and its clinical significance: Potential biomarkers for LSCC. PLoS One 9: e108237, 2014.

15. Wang J, Zhou Y, Lu J, Sun Y, Xiao H, Liu M and Tian L: Combined detection of serum exosomal miR-21 and HOTAIR as diagnostic and prognostic biomarkers for laryngeal squamous cell carcinoma. Med Oncol 31: 148, 2014.

16. Zhao J, Lv K, Li ZH, Wu J, Gao W, Wong TS, Luo J, Qin H, Wang B, Fu Q and Lei WB: Functional significance of the long non-coding RNA RP11-169D4.1 as a metastasis suppressor in laryngeal squamous cell carcinoma by regulating $\mathrm{CDH} 1$. Oncol Rep 38: 211-220, 2017.

17. Klein RJ, Halldén C, Cronin AM, Ploner A, Wiklund F, Bjartell AS, Stattin P, Xu J, Scardino PT, Offit K, et al: Blood biomarker levels to aid discovery of cancer-related single-nucleotide polymorphisms: Kallikreins and prostate cancer. Cancer Prev Res (Phila) 3: 611-619, 2010.

18. Ronald JA, Chuang HY, Dragulescu-Andrasi A, Hori SS and Gambhir SS: Detecting cancers through tumor-activatable minicircles that lead to a detectable blood biomarker. Proc Natl Acad Sci USA 112: 3068-3073, 2015.

19. Mehlen P and Puisieux A: Metastasis: A question of life or death. Nat Rev Cancer 6: 449-458, 2006.

This work is licensed under a Creative Commons Attribution-NonCommercial-NoDerivatives 4.0 International (CC BY-NC-ND 4.0) License. 